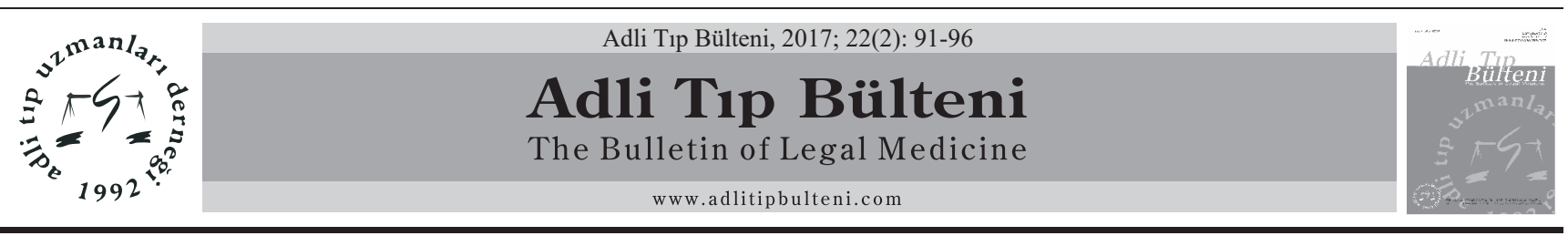

\title{
Bilgisayarlı Tomografi ile Frontal Sinüs Morfometrik Analizinin Cinsiyet Belirlenmesinde Kullanımı
}

\section{Use of Frontal Sinus Morphometric Analysis by Computerized Tomography in Sex Determination}

\author{
Ŏguzhan Ekizoğlu ${ }^{1}$, Elif Hocaoğlu², Ercan Inci ${ }^{2}$ \\ ${ }^{1}$ Tepecik Eğitim ve Araştırma Hastanesi, Adli Tip Birimi, İzmir \\ ${ }^{2}$ Bakırköy Dr. Sadi Konuk Eğitim ve Araştırma Hastanesi, Radyoloji Kliniği, İstanbul
}

\begin{abstract}
Özet
Amaç: Bu çalışmanın amacı, frontal sinüs boyutlarının bilgisayarlı tomografi ile yapılan ölçüm sonuçlarının, cinsiyetin belirlemesinde yararlılığını değerlendirmektir.

Gereç ve Yöntem: Çalışmaya Bakırköy Dr. Sadi Konuk Eğitim ve Araştırma Hastanesi'nde maksillofasiyal bilgisayarlı tomografi çekimi yapılan olgular dahil edildi. Transvers çapları (genişlik; RT ve LT) eksensel görüntülerden, ön-arka (derinlik; RAP ve LAP) ve sefalo-kaudal çaplardan (yükseklik; RH ve LH) sagital yeniden biçimlendirilmiş görüntülerden ölçüldü. Hem sol hem de sağ frontal sinüsler için ölçümler yapıldı. Her iki taraf frontal sinüs boyutu bu parametreler kullanılarak elde edildi. Değerler bağımsız t testi ile., değişkenler diskriminant fonksiyon analizi ile değerlendirildi.

Bulgular: Çalışma için 400 olgu değerlendirildi (200 erkek 200 kadın, ortalama yaş: $44 \pm 18.0$ ) Sol ve sağ ölçümlerin tüm değerleri cinsiyete göre anlamlı fark gösterdi. Erkekler, kadınlara kıyasla belirgin artmış bir ölçüm değeri taşıyordu. $(\mathrm{p}<0.001)$ Tekli diskriminasyon analizinde en düşük doğruluk oranı erkeklerde LH için \%55.5, kadınlarda RT için \%59.5 idi. Kadınlarda LAP (\%77.5) ve RAP (\%77) ve erkeklerde LAP (\%69) en yüksek doğruluk oranlarına sahipti. Yalnızca RAP ve LAP değerleri eklendiğinde diskriminasyon analizinde doğruluk oranı kadınlarda \%77.5, erkeklerde $\% 70.5$ olarak tespit edildi. Aşamalı diskriminasyon analizinde ölçülen değerlerin hepsi dahil edildiğinde, doğruluk oranı kadınlarda \%80.5, erkeklerde \%71.5 olarak tespit edildi.

Sonuç: Özellikle çok kültürlü toplumlarda frontal sinüs morfometrik çalışmaları kimliklendirme araştırmaları için önemli veriler sağlayabilir. Veriler, adli tıp uzmanları ve antropologların yanı sıra ilgili anatomik yapılarda endoskopik ve cerrahi işlemler gerçekleştiren kraniyofasiyal cerrahlar ve diş hekimleri için de yararlı olacaktır.

Anahtar Kelimeler: Frontal Sinüs; Cinsiyet Tayini; Bilgisayarlı Tomografi..
\end{abstract}

\section{Giriş}

Antropometrik çalışmalar kimliklendirmede temel analiz metotlarından biridir. DNA analizi ve bazen parmak izi gibi metotların kimliklendirmede kullanımı kesin

Sorumlu Yazar: Uzm. Dr. Oğuzhan Ekizoğlu

Tepecik Eğitim ve Araştırma Hastanesi, Adli Tip Birimi, İzmir

E-mail:drekizoglu@gmail.com

Geliş:28.03.2017 Düzeltme:07.04.2017 Kabul:09.04.2017

\begin{abstract}
Objective: The aim of this study is to evaluate usefulness of results of measurements via computerized tomography of frontal sinus dimensions in sex determination.

Materials and methods: In Bakırköy Training and Research Hospital, subjects who had performed maxillofacial computed tomography were included. Transvers diameters (width) were measured from axial images and anterior-posterior (depth) and cephalo-caudal diameters (height) were measured from sagittal reformatted images. Measurements were taken for both left and right frontal sinuses. The size of frontal sinuses on both sides were obtained using these parameters. These values were evaluated with independent $t$ test. The variables were evaluated discrimination function analysis
\end{abstract}

Results: 400 subjects were evaluated (200 males and 200 females) for the study (female/male: 200/200, mean age: $30.12 \pm 10.2$ years of age). All values for left and right transvers, cephalo-caudal and antero-posterior measurements showed significant differences between the sexes of the subjects. Males had significant increased values than females $(\mathrm{p}<0.001)$. In single discrimination analysis, the lowest accuracy rate was $55.5 \%$ for LH in males and $59.5 \%$ for RT in females. Highest observed accuracy rates were LAP (77.5\%) and RAP (77\%) in females and LAP $(69 \%)$ in males. When, only the RAP and LAP values were added together, the accuracy rate was detected as $77.5 \%$ in females and $70.5 \%$ in males. If all measured values were included in the stepwise discrimination analysis, then the accuracy rate was detected as $80.5 \%$ in females and $71.5 \%$ in males.

Conclusion: The frontal sinus morphometric studies, particularly in multicultural societies, can provide important data for research. The data will be useful for forensic specialists and anthropologists, as well as craniofacial surgeons and dentists who perform endoscopic and surgical procedures in related anatomical structures.

Keywords: Frontal Sinus; Sex Determination; Computerized Tomography.

verilere ulaşmayı sağlasa da postmortem yumuşak dokunun farklı nedenlerle kaybı antropometrik ölçümleri başlıca inceleme yöntemi haline getirir (1). Çürüme, yanma ve farklı kimyasallar ile oluşan yumuşak doku harabiyeti sonucu kimliklendirmede iskelet kalıntılarının radyolojik incelemeleri önemli bilgiler sunar (2). Cinsiyet tespiti kimliklendirmenin önemli bir aşamasıdır ve özellikle kraniyofasiyal morfometrik incelemeler; iskelet kalınt1- 
larının ileri derecede bütünlüğünü kaybettiği durumlarda ön planda değerlendirilir (3). Kraniyofasiyal alanda frontal sinüs bireye özgü yapıdadır ve anatomik yapısı ağır patolojik durumlar (travma, ağır infeksiyon, cerrahi girişim vb) dışında 18 yaş sonrası değişim göstermez (48). Frontal sinüs anatomisi, kademeli pnömatizasyonun atrofik değişikliklerden oluştuğu ileri yaşlara kadar yaşam boyunca stabil kalır (9). Monozigot ikizlerde bile her insana özgü frontal sinüs radyografik modelinin benzersizliği, daha önceki çalışmalarda saptanmıştır $(6,8,10)$. Frontal sinüsler pnömatik paranazal sistemin en değişken bölümüdür ve şekil, simetri ve gelişim derecesinde büyük farklar gösterir (11). En yüksek değişkenlik yalnızca tek tek kafatasları arasında değil aynı zamanda farklı pozisyonlardaki tek bir kafatasında da görülür (12).

Frontal sinüsün morfometrik analizleri, cinsiyet ay1rımı için kimliklendirmede sık uygulanan bir metottur. Kimliklendirme çalışmalarında frontal sinüsün radyografik incelemesinde sıklıkla uygulanan direkt grafilerin yanında son y1llarda bilgisayarlı tomografi (BT) kullanımı başarılı bir yöntem olarak kabul görmektedir (15-19).

$\mathrm{Bu}$ çalışmada frontal sinüsün ince kesit BT kullanılarak morfometrik analizinin Türkiye toplumunda cinsiyet ayırımı açısından değerlendirilmesi ve adli tıbbi kullanılabilirliği araştırılmıştır.

\section{Gereç ve Yöntem}

Bu çalışmada Bakırköy Dr. Sadi Konuk Eğitim ve Araştırma Hastanesi'ne 2014-2016 tarihleri arasında başvuran ve maksillofasiyal BT incelemesi yapilan hastalar retrospektif olarak incelenmiştir. Frontal sinüs bilateral yokluğu, kraniyofasiyal alanda travma ve kırık, cerrahi girişim öyküsünün tespit edildiği olgular çalışma dışında tutulmuştur. Ek olarak frontal sinüs gelişiminin tamamlanması açısından 18 yaş altı çalışmaya alınmamıştır. Çalışmaya 18-45 yaş (ortalama yaş: $30.12 \pm 10.2) 400$ hasta (200 erkek ve 200 kadın) dahil edilmiştir.

Bilgisayarlı tomografi analizleri için 128-kesit bilgisayarlı tomografi cihazı (Siemens Medical Solutions, Enlargen, Germany) kullanılmıştır. Tüm taramalar hastaların supin pozisyonda alınmış ve tüp voltajı $120 \mathrm{kV}$; efektif mAs, 150; kesit kalınlığ $1 \mathrm{~mm}$; ve rekonstrükte görüntülerde aynı şekilde $1 \mathrm{~mm}$ kesit kalınlığ kullanılmıştır. Veriler kemik algoritmi ile rekonstrükte edilerek aksiyal ve sagital planlar değerlendirilmiştir. Tüm görüntüler iş istasyonuna alındıktan sonra frontal sinüs üzerinde ölçümler yapılmıştır. Transvers çaplar (geniş̧lik; sağ ve sol için sırasıyla RT ve LT) aksiyal görüntülerden ölçüldü (Resim 1), ön-arka (derinlik; sağ ve sol için sırasıyla RAP ve LAP) ve sefalo-kaudal çaplar (yükseklik; sağ ve sol için sırasıyla RH ve LH) sagital yeniden biçimlendirilmiş görüntülerden ölçüldü (Resim 2). Genişlik, orbita çatı seviyesinde aksiyal kesitler boyunca ölçülen maksimum mesafe idi. Yükseklik, frontal sinüs ostiumundan maksimum yüksekliğe olan mesafe idi. Derinlik, yükseklik çizgisine ortogonal olan ön ve arka alan arasındaki maksimum mesafeydi. Hem sol hem de sağ frontal sinüsler için ölçümler yapıldı. Her iki taraftaki frontal sinüslerin boyutu bu parametreler kullanılarak elde edildi.

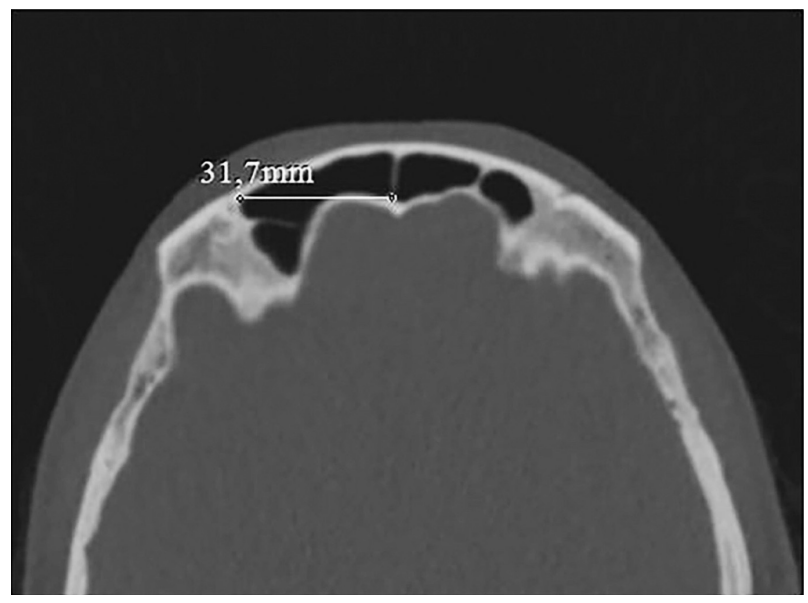

Resim 1. Aksiyal bilgisayarlı tomografi görüntüsü: transvers uzunluk ölçümü (31.7 mm)

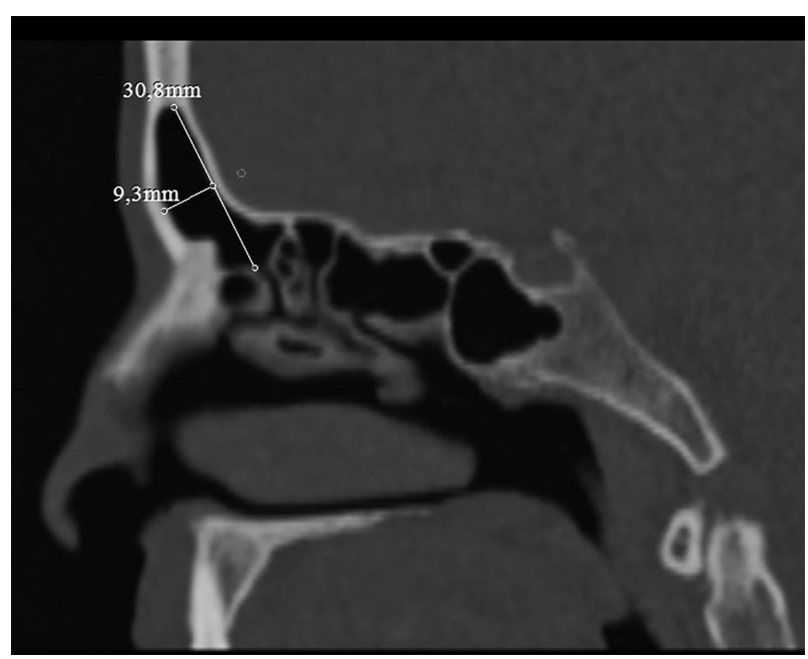

Resim 2. Sagital yeniden biçimlendirilmiş bilgisayarlı tomografi görüntüsü: antero-posterior $(9.3 \mathrm{~mm})$ ve sefalokaudal (30.8 mm) çap ölçümü

Çalışmada tüm ölçümler radyoloji uzmanı tarafından gerçekleştirildi. İlk ölçümlerden bir ay sonra rastgele seçilmiş 50 olgu tekrar aynı araştırmacı tarafından değerlendirildi. İlk ve ikinci değerlendirme sonucu elde edilen ölçüm değerleri üzerinden kappa analizi yapılarak intraobserver hata oranı belirlendi. 
Tablo 1. Cinsiyetlere göre frontal sinus ölçüm değerleri ve karşılaştırılması

\begin{tabular}{|l|l|l|l|l|l|}
\hline & \multicolumn{2}{|c|}{ Kadın } & \multicolumn{2}{c|}{ Erkek } & \\
\hline & Ölçüm aralığ 1 & Ortalama \pm SD & Ölçüm aralığ1 & Ortalama \pm SD & $P$ \\
\hline RT & $8.2-52.8$ & $27.7 \pm 8.6$ & $13.7-66.3$ & $32.5 \pm 8.8$ & $<0.001$ \\
\hline RH & $16.2-49.3$ & $29.2 \pm 6.0$ & $18.8-49.7$ & $32.7 \pm 6.1$ & $<0.001$ \\
\hline RAP & $5.0-15.0$ & $9.5 \pm 2.0$ & $5.9-23.2$ & $12.5 \pm 2.9$ & $<0.001$ \\
\hline LT & $9.3-59.3$ & $29.0 \pm 9.7$ & $13.9-60.0$ & $33.4 \pm 9.1$ & $<0.001$ \\
\hline LH & $18.0-58.8$ & $29.9 \pm 6.7$ & $18.2-52.0$ & $32.8 \pm 6.0$ & $<0.001$ \\
\hline LAP & $4.8-15.0$ & $9.6 \pm 2.0$ & $6.5-24.0$ & $12.75 \pm 2.8$ & $<0.001$ \\
\hline
\end{tabular}

Tablo 2. Sol ve sağ frontal sinus için karşılaştırmalı analiz

\begin{tabular}{|l|l|l|}
\hline & \multicolumn{2}{|c|}{ P değeri } \\
\hline & Kadın & Erkek \\
\hline RT vs LT & 0.65 & 0.183 \\
\hline RAP vs LAP & 0.472 & 0.118 \\
\hline RH vs LH & 0.98 & 0.907 \\
\hline
\end{tabular}

Çalışmada elde edilen verilerin ortalama ve standart deviasyon değerleri ölçülerek cinsiyetler arası farklılıkların tespiti için independent $t$ test kullanılmıştır. Ölçümlerdeki değişkenler için diskriminasyon analizi, SPSS Program1 (Version 17; SPSS Inc., Chicago, IL) kullanılarak yapılmıştır.

\section{Bulgular}

Çalışmaya 18-45 yaş (ortalama yaş: $30.73 \pm 11.2$ ) 400 hasta dahil edilmiştir. Cinsiyete göre frontal sinüs ölçümlerinde erkek cinsiyette tüm ölçüm değerlerinin kadın cinsiyete göre daha büyük olduğu saptandı. Tüm ölçüm değerlerinde istatistiksel olarak anlamlı farklılık olduğu saptanmıştır. $(\mathrm{p}<0.001)$ (Tablo 1). Sağ ve sol sinüs ölçümleri cinsiyetlere göre karşılaştırıldığında sağ ve sol tarafın ölçümlerinde her iki cinsiyette de anlamlı bir fark saptanmadi (Tablo 2).

Frontal sinüs için hesaplanan kanonikal diskriminant fonksiyon değerleri hesaplanmış ve tablo 3'te sunulmuştur. Ölçülen değerler için tekli diskriminasyon analizinde elde edilen doğruluk oranlarında kadınlarda en düşük oran \%59.5 ile RT ve erkeklerde 55.5 ile LH ölçümünde saptandı. En yüksek doğruluk oranları ise kadınlarda \%77.5 ile LAP ve \%77 ile RAP ölçümlerinde izlenirken erkeklerde en yüksek değer \%69 ile LAP ölçümünde saptandi.

Ölçümler için yapılan aşamalı diskriminasyon analizinde RAP ve LAP'nin dahil edildiği analizde kadınlarda $\% 77.5$ ve erkeklerde $\% 70.5$ doğruluk oranı tespit edildi. Tüm ölçüm değerlerinin dahil edildiği aşamalı diskriminasyon analizinde ise kadınlarda $\% 80.5$ ve erkeklerde $\% 71.5$ oranlarında doğruluk oranı tespit edildi. Tüm ölçüm değerleri için tekli ve aşamalı diskriminasyon analizi sonucu elde edilen doğruluk oranları tablo 4 de sunulmuştur.

Çalışmada yapılan intraobserver analiz sonucunda kappa değeri 0.828 olarak belirlenmiş olup, iyi bir uygulanabilirlik ve tekrarlanabilirlik değerini işaret etmektedir.

\section{Tartışma}

İskelet üzerinde cinsiyet ayırımında morfometrik analizler yüksek sınıflandırma ile hızlı bir şekilde doğruluk sunabilir. Kafatası mevcut ise $\% 92$, pelvis varlığında $\% 95$ ve her ikisinin varlığında $\% 98$ oranlarında doğruluk elde edilebilir (13). İskeletin bütünlüğünü kaybettiği her türlü durumda kafatası bütünlügünü koruyabilmesi ve özellikle sinüs yapılarının kafa içi yerleşim avantajları ile travmatik etkilerden daha fazla korunması önemlidir (3-8). Modern tıp uygulamalarında giderek daha sıklıkta uygulanan CT ince kesit avantaj1, yüksek çözünürlük ve üç boyutlu modelleme avantaj 1 ile iskelet sistemi ile ilgili ayrıntılı bilgiler sunmaktadır. Royal College raporunda yıllara göre BT uygulamalarının çok fazla arttığı gösterilmiştir (14). Bu teknik avantajların yanında yaşayan bireylerde farklı klinik endikasyonlar ile yüksek sayılarda uygulanan BT görüntülerinin, popülasyon verilerinin oluşturulması için antropometrik çalışmalar için önemli bir kaynak olduğunu düşünüyoruz. Yaşayan bireylerin BT analiz verilerine dayanan morfometrik çalışmalar hem modern toplumların verilerini ortaya koyması hem de buluntu kemiklerin incelenmesi için önerilebilir ve bu konuda giderek artan sayıda çalışmalar mevcuttur (15-24).

Çalışmamız ile modern Türkiye toplumunda frontal sinüs ölçümlerinin cinsiyetler arası farklılıkları araşt1rılmıştır. Frontal sinüsün genişlik, derinlik ve yükseklik ölçümleri değerlendirilmiş olup, tüm ölçüm değerlerin- 
Tablo 3. Frontal sinüs ölçüm değerleri için discriminant fonksiyon değerleri

\begin{tabular}{|l|c|c|c|c|c|c|}
\hline & RT & RH & RAP & LT & LH & LAP \\
\hline Eigen values & 0.76 & 0.84 & 0.350 & 0.550 & 0.050 & 0.402 \\
\hline \%of variance & 100 & 100 & 100 & 100 & 100 & 100 \\
\hline Cumulative \% & 100 & 100 & 100 & 100 & 100 & 100 \\
\hline Canonical correlation & 0.266 & 0.279 & 0.509 & 0.228 & 0.219 & 0.536 \\
\hline Wilks lambda & 0.929 & 0.922 & 0.741 & 0.948 & 0.952 & 0.713 \\
\hline Chi-square & 29.1 & 32.1 & 119.4 & 21.1 & 19.5 & 134.3 \\
\hline Significance & $<0.001$ & $<0.001$ & $<0.001$ & $<0.001$ & $<0.001$ & $<0.001$ \\
\hline SC & 1.0 & 1.0 & 1.0 & 1.0 & 1.0 & 1.0 \\
\hline
\end{tabular}

Tablo 4. Diskriminasyon analizi sonucu elde edilen doğruluk oranları

\begin{tabular}{|c|c|c|c|c|c|}
\hline \multirow{2}{*}{\multicolumn{3}{|c|}{$\begin{array}{c}\text { Grup } \\
\text { Kadın } \\
\text { Erkek }\end{array}$}} & \multicolumn{2}{|c|}{$\begin{array}{c}\text { Doğruluk } \\
\text { oranları }\end{array}$} & \multirow{3}{*}{$\begin{array}{l}\text { Toplam } \\
100 \\
\end{array}$} \\
\hline & & & & & \\
\hline \multirow{2}{*}{ RT } & \multirow{2}{*}{$\%$} & Kadın & 59.5 & 40.5 & \\
\hline & & Erkek & 40.5 & 59.5 & 100 \\
\hline \multirow{2}{*}{ RH } & \multirow{2}{*}{$\%$} & Kadın & 68.0 & 32.0 & 100 \\
\hline & & Erkek & 40.5 & 59.5 & 100 \\
\hline \multirow{2}{*}{ RAP } & \multirow{2}{*}{$\%$} & Kadın & 77.0 & 23.0 & 100 \\
\hline & & Erkek & 34.0 & 66.0 & 100 \\
\hline \multirow{2}{*}{ LT } & \multirow{2}{*}{$\%$} & Kadın & 61.0 & 39.0 & 100 \\
\hline & & Erkek & 43.5 & 56.5 & 100 \\
\hline \multirow{2}{*}{ LH } & \multirow{2}{*}{$\%$} & Kadın & 66.0 & 34.0 & 100 \\
\hline & & Erkek & 44.5 & 55.5 & 100 \\
\hline \multirow{2}{*}{ LAP } & \multirow{2}{*}{$\%$} & Kadın & 77.5 & 22.5 & 100 \\
\hline & & Erkek & 31.0 & 69.0 & 100 \\
\hline \multirow{2}{*}{$\begin{array}{l}\text { Aşamalı } \\
\text { analiz } \\
\text { (RAP ve } \\
\text { LAP) }\end{array}$} & \multirow[b]{2}{*}{$\%$} & Kadın & 77.5 & 22.5 & 100 \\
\hline & & Erkek & 29.5 & 70.5 & 100 \\
\hline \multirow{2}{*}{$\begin{array}{l}\begin{array}{l}\text { Aşamalı } \\
\text { analiz }\end{array} \\
\text { (RT, RH, } \\
\text { RAP, LT, } \\
\text { LH ve LAP) }\end{array}$} & \multirow[b]{2}{*}{$\%$} & Kadın & 80.5 & 19.5 & 100 \\
\hline & & Erkek & 28.5 & 71.5 & 100 \\
\hline
\end{tabular}

de her iki frontal sinüs ölçümleri erkeklerde kadına göre istatistiki olarak anlamlı düzeyde yüksek bulunmuştur $(p<0.001)$. Lee ve ark. (16) ve Hamed ve ark. (20) frontal sinüs BT morfometrik analizlerinde benzer şekilde frontal sinüs ölçüm parametrelerinin erkek cinsiyette istatistiki olarak anlamlı düzeyde yüksek olduğunu bildirmişlerdir. Mathur ve ark. (17) genişlik ve yükseklik ölçümlerinde, Johnson ve ark (18) ve Ponde ve ark (19) ise anteroposterior ve transvers ölçümlerin erkeklerde istatistiki olarak anlamlı düzeyde yüksek olduğunu bildirmiştir.

Çalışmamızda elde edilen veriler ile yapılan tekli diskriminasyon analizi sonucunda kadın cinsiyet üzerine en çok belirleyici olan faktörlerin \%77.5 ile LAP ve $\% 77$ ile RAP olduğu tespit edilmiştir. Diğer taraftan erkek cinsiyet için en yüksek doğruluk oranları \%69 ile RAP değerlerinde tespit edilmiştir. Uthman ve ark (15) yaptıkları çalışmada erkek ve kadın cinsiyet için ortalama doğruluk oranlarını sırasıyla \%78 ve \%75.7 olarak bildirmiştir. Çalışmamızda aşamalı diskriminasyon analizinde RAP ve LAP'nin dahil edildiği analizde kadınlarda $\% 77.5$ ve erkeklerde $\% 70.5$ doğruluk oranı tespit edilirken tüm ölçüm değerlerinin dahil edildiği aşamalı diskriminasyon analizinde ise kadınlarda $\% 80.5$ ve erkeklerde $\% 71.5$ oranlarında doğruluk oranları tespit edildi. Sonuçlar, frontal sinüs morfometrik analizinin farklı toplumlarda yapılan analiz sonuçları ile benzerlik göstermektedir. Ancak frontal sinüsün tek başına değerlendirildiği kimliklendirme olgularında elde edilen verilere dikkatli yaklaşmak gereklidir. Farklı iskelet alanlarında elde edilen yüksek doğruluk oranlarına göre cinsiyet ayırımında doğruluk oranlarının \%80'in altında olması açısından dikkat çekicidir. Ancak kraniyofasiyal alanda maksiller sinüs değerlendirmelerinde de frontal sinüse yakın değerler gösterilmiştir. Teke ve ark. (22) maksiller sinüs için BT analizine dayanan çalışmasında doğruluk oranlarını erkeklerde \%69.3\%ve kadınlarda \%69.4 olarak bildirmiştir. Buna karşın Türkiye popülasyonunda yapılan diğer bir maksiller sinüs BT çalışmasında Ekizoğlu ve ark (21) erkeklerde \%74.3 ve kadınlarda \%80 doğruluk oranı bildirmiştir. Bu durum çalışma yapılan popülasyonun sayısı ve çalışma yapılan bölgelerin farklılığından kaynaklanabilir. Ancak bu farklılığın açıklanabilmesi için karşılaştırmalı verilerin etnik köken ve sosyoekonomik durumu kapsar şekilde 
yapılması gerekir. Fernandes ve ark. (23) yaptı̆̆ parametreli kranium çalışmasında maksiller sinüs için doğruluk oranını \%79.2 olarak bildirirken Deshmukh ve ark. (24) maksiller sinüsü içeren 16 parametreli analiz çalışmasında ise ortalama doğruluk oranını $\% 80-87$ olarak bildirmiștir.

Frontal sinüs morfometrik değerlendirmesi cinsiyet tayini için önemli bir parametre olarak izlenmiştir. Kraniyal inceleme alanında ölçülen parametrelerin çoğaltılması güvenilirlik oranını artırabilir. Çalışmamızda frontal sinüs morfometrik verileri kimliklendirme için önemli veriler sunmaktadır ve BT analizinde $1 \mathrm{~mm}$ 'lik ince kesitler cinsiyet tayini yapılmasında verilerin doğruluğu üzerinde etkilidir. Diğer taraftan kafatasının ileri derecede travmatize olduğu inceleme durumlarında cinsiyet tayini için frontal sinüsün BT ile morfometrik incelemesi, geleneksel antropometrik inceleme yöntemlerine göre hızlı bir analiz olabilir. Bu çalışmanın hazırlanmasında retrospektif bir analiz kullanıldığ 1 için etnik köken ve sosyoekonomik duruma ulaşılamamıştır ve bu durum çalışmamız için bir kısıtlılıktır. Çalışmada, BT analizlerinin radyoloji uzmanı tarafından yapılmış ve interobserver analizin yapılmamış olması k1sıtll1ık olarak görünse de intraobserver analizlerde elde edilen 0.828 kappa değeri metodun güvenilirliği ve tekrarlanabilirliği açısından yeterli görünmektedir. Frontal sinüs morfometrik analizi için BT ve iş istasyonlarının kullanımı tanısal bir değerlendirme gerektirmediğinden, adli tıp uzmanları ve adli antropologlar için kolaylıkla öğrenilebilir ve uygulaması başarılı sonuçlar verebilir (2).

Karşılaştırmalı frontal sinüs morfometrik çalışmalarının artması araştırmacılara önemli veriler sunabilir. Frontal sinüsün morfometrik analizi cinsiyet tayini için adli tıp uzmanları ve antropologlara yardımcı olduğu gibi kraniyofasiyal cerrahlar ve diş hekimlerine de anatomik varyasyonları göstermesi açısından önemli bilgiler verebilir.

\section{Kaynaklar}

1. Carvalho SPM, Alves da Silva,RH, Lopes-Júnior C, Peres AS. Use of images for human identification in forensic dentistry. Radiol. Bras. 2009;42(2):125-130. doi: 10.1590/ S0100-39842009000200012

2. Pfaeffli M, Vock P, Dirnhofer, Braun M, Bolliger SA, Thali MJ. Post-mortem radiological CT identification based on classical ante-mortem X-ray examinations, Forensic Sci. Int. 2007;171:111-117. doi: 10.1016/j.forsciint.2006.10.009

3. Rogers T. Determining the sex of human remains through cranial morphology. J Forensic Sci. 2005;50(3):493-500. doi: $10.1520 / J F S 2003385$

4. Cameriere R, Ferrante L, Mirtella D, Rollo FU, Cingolani M. Frontal sinuses for identification: quality of classificati- ons, possible error and potential corrections. J Forensic Sci. 2005;50(4):770-3. doi: 10.1520/JFS2004343

5. Yoshino M, Miyasaka S, Sato H, Seta S. Classification system of frontal sinus patterns by radiography: its application to identification of unknown skeletal remains, Forensic Sci. Int. 1987;34:289-299. doi: 10.1016/03790738(87)90041-7

6. Quatrehomme G, Fronty P, Sapanet M, Grevin G, Bailet P, Ollier A. Identification by frontal sinus pattern in forensic anthropology. Forensic Sci. Int. 1996;83:147- 153. doi: 10.1016/S0379-0738(96)02033-6

7. Ribeiro FAQ. Standardized measurements of radiographic films of the frontal sinuses: an aid to identifying unknown persons, Ear, Nose Throat J. 2000;79:26-33.

8. Kirk NJ, Wood RE, Goldstein M. Skeletal identification using the frontal sinus region: a retrospective study of 39 cases, J Forensic Sci. 2002;47:318-323. doi: 10.1520/ JFS15250J.

9. Hyzer W, Anthony A, Sperry K, Marlin D, Bonnell H, Haglund W, et al. "Letters to the Editor," Journal of Forensic Sciences, 1992;37(5): 1203-1215 doi: 10.1520/JFS13307J.

10. Nambiar P, Naidu MDK, Subramaniam K. Anatomical variability of the frontal sinuses and their application in forensic identification, Clin. Anat. 1999;12:16- 19. doi: 10.1002/ (SICI)1098-2353(1999)12:1<16::AID-CA3>3.0.CO;2-D

11. Teul I, Czerwiski F, Cyryowski L, Sawiski G, Miklaszewska D. Morphologic evaluation of the paranasal sinuses of the skulls from different historic periods. Durham Anthropol. J. 2005;12:2-3

12. Riepert T, Ulmcke D, Schweden F, Nafe B. Identification of unknown dead bodies by X-ray image comparison of the skull using the X-ray simulation program Foxsis, Forensic Sci. Int. 2001;117:89-98. doi: 10.1016/S03790738(00)00452-7

13. Krogman WM ve Iscan MY. The Human Skeleton in Forensic Medicine, Charles C.Thomas, Springfield, Ill, USA, 1986.

14. The Royal College of Radiologists. Investing in the clinical radiology workforce - The quality and efficiency case. 2012 URL: https://www.rcr.ac.uk/docs/radiology/ pdf/RCR_CRWorkforce_June2012.pdf Son Erişim Tarihi: 06.08.2016

15. Uthman AT, Al-Rawi NH, Al-Naaimi AS, Tawfeeq AS, Suhail EH. Evaluation of frontal sinus and skull measurements using spiral CT scanning: an aid in unknown person identification. Forensic Sci Int. 2010;197(1-3):124.e1-7. doi: 10.1016/j.forsciint.2009.12.064

16. Lee MK, Sakai O, Spiegel JH. CT measurement of the frontal sinus - gender differences and implications for frontal cranioplasty. J Craniomaxillofac Surg. 2010;38(7):494-500. doi: 10.1016/j.jcms.2010.02.001

17. Mathur H, Mathur A, Ahmed J, Khorate M, Tripathi P. Conventional frontal Sinus imaging in identification of sex : Original study in population of Udaipur City ,India. Journal of Medical Science and Clinical Research 2013;1(1):33-37

18. Sahlstrand-Johnson P, Jannert M, Strömbeck A, Abul-Kasim K. Computed tomography measurements of different dimensions of maxillary and frontal sinuses. BMC Med Imaging. 2011;11:8. doi: 10.1186/1471-2342-11-8 
19. Pondé JM, Metzger P, Amaral G, Machado M, Prandini M. Anatomic variations of the frontal sinus. Minim Invasive Neurosurg. 2003;46(1):29-32. doi: 10.1055/s-2003-37956

20. Hamed S, El-Badrawyb AM, Abdel Fattah S. Gender identification from frontal sinüs using multi-detector computed tomography. Forensic Radiology and Imaging 2014;2(3):117-120 doi: 10.1016/j.jofri.2014.03.006

21. Ekizoglu O, Inci E, Hocaoglu E, Sayin I, Kayhan FT, Can IO. The use of maxillary sinus dimensions in gender determination: a thin-slice multidetector computed tomography assisted morphometric study. J Craniofac Surg. 2014;25(3):957-60. doi: 10.1097/scs.0000000000000734
22. Teke HY, Duran S, Canturk N, et al. 1. Determination of gender by measuring the size of the maxillary sinuses in computerized tomography scans. Surg Radiol Anat 2007;29:9-13. doi: 10.1007/s00276-006-0157-1

23. Fernandes CL. Forensic ethnic identification of crania. The role of the maxillary sinus - a new approach. Am J Forensic Med Pathol 2004;25(4):302-13. doi: 10.1097/01. paf.0000146379.85804.da

24. Deshmukh AG, Deversh DB. Comparison of cranial sex determination by univariate and multivariate analysis. J Anat Soc India 2006;55(2):1-5. 